\title{
1992-A symbolic year for European science
}

\begin{abstract}
In 1992, many European nations will begin to act as a unity under the banner of the European Economic Community. The new spirit of cooperation will have dramatic impacts in economic, social, and political matters. The movement also offers manifold opportunities for promoting increased regional and worldwide cooperation and communication in scientific research.
\end{abstract}

In 1492, almost 500 years ago, America was discovered by Europeans. For 1992, there is a plan for a new Western Europe without frontiers. and there are some indications that America and Japan more and more will be discovering Western Europe and its 400 million inhabitants as a possible unity. Economically, the driving force for this movement to unity will be the 12-nation European Economic Community (EC) that has its administration in Brussels, Belgium.

EC has about 320 million inhabitants compared to 240 million in the USA and 120 million in Japan. but in 1984. EC had a gross national product of only about US $\$ 2,500$ billion compared to US $\$ 3,700$ billion in the USA and US $\$ 1,200$ billion in Japan. EC in 1985 spent only 1.9 percent of its gross national product on research and development; this compares to about 2.8 percent and 2.6 percent, respectively, in the USA and Japan. In 1980, there were only 12 scientists and engineers per 1,000 inhabitants in the EC countries but about 29 in the USA and 32 in Japan. For many Europeans. these figures are challenging and provide a chance, with great resourcefulness, to improve economic and scientific potentials; 1992, therefore, becomes a symbol for such an evolution.

Surprisingly, the so-called "Old House of Europe," another symbol that includes Eastern Europe, became visible in a dramatic way during the last months of 1989. In this historical situation, it is impossible to predict the outcome, at least it is for a geologist who is trained to analyze the past and not the future. Therefore, I would like to give some information on various past and ongoing methods to improve European cooperation in research, especially in the geosciences.

\section{Variety stimulates research}

First of all. I have to stress the fact that a great variety of attitudes and methods exist in Europe. For several centuries, Europe has developed politically more centrifugal forces than centripetal ones, more nationalistic attitudes than European ones. This is true for the sciences too. Many of the smaller European countries have figures that differ greatly from those quoted above for the EC as a whole, and this again provides an opportunity to improve the existing situation. Additionally, most countries traditionally feel that research is an important factor within society. Powerful national organizations promote research in many excellent universities and research institutes even though funding is under strain. Many researchers in these national institutions cooperate on a binational or even a multinational basis. I would hate to see an end in European basic science to the existing variety of ideas, methods, arguments, and even personalities that originate from national influences. We have seen that part of the successes in North American science also have resulted from a variety of influences.

\section{Promoting cooperation}

I would like to mention four groups that promote this trend toward communication and cooperation in research in European countries. (1) Europe has more than 300 "Learned Societies" that cover all branches of research. The European Union of Geosciences (EUG), for example, organizes a biannual congress in Strasbourg. France, which attracts about 2,000 researchers from all fields of solid earth sciences. A periodical, Terra Nova, is published regularly. Similar but informal groups cooperate in more specialized fields under the chairmen of Western Europe's geological surveys. (2) The governmental Commission of the EC (CEC) in Brussels stimulates cooperation by various programs in which the earth sciences play a role, especially in environmental problems and mineral resources. In addition, a Stimulation Program that was in effect from 1985 through 1988 is developing into a Science Program that plans to spend some US\$600 million from 1990 through 1994 for "Human Capital and Mobility." Unfortunately, only a few applications have been received, and until now, grants have been given only to earth scientists. (3) Several large European research facilities have worldwide reputations, as, for example, since 1954. the European Laboratory for Particle Physics (CERN) in Geneva. Switzerland; since 1974. the European Molecular Biology Laboratory (EMBL) in Heidelberg. Germany; and since 1977, the Joint European Torus (JET) in Culham. England. European cooperation in space has been promoted since 1975 by the European Space Agency (ESA) in Paris, France. Nothing comparable exists for the earth sciences, but plans are that a European research vessel (NEREIS) will perform marine geology experiments and observations and some shallow sea-floor drilling. (4) The European Science Foundation (ESF). established in 1974, is an association that has a membership of some 50 research councils and academies from 20 Western European countries. Recently, the Hungarian Academy of Science became a member too. ESF is a nongovernmental organization. as is the International Union of Geological Sciences (IUGS), and, therefore, is by definition a concentration hopefully of intelligence although certainly not of money.

\section{European Science Foundation}

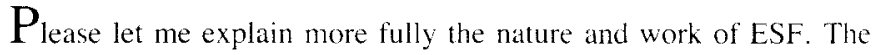
ESF brings European scientists together to work on topics of common concern, to share in the use of expensive facilities, and to discover new endeavors that will benefit from a cooperative approach. The scientific work sponsored by ESF includes basic research in the natural sciences, in medicine and the biosciences, and in humanities and the social sciences. The earth sciences are becoming an impor- 


\section{european}

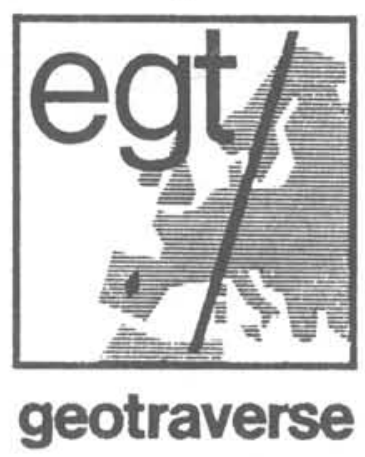

tant component as well. ESF now has nearly 20 networks and some 2,000 participants in all scientific fields.

The first activities for cooperative investigations normally are small workshops for specialists. Proposals for so-called networks or for scientific activities may result from these meetings. For example, the European Geotraverse (EGT) (see logo illustration) was 1 of 16 such activities. The multidisciplinary work of EGT began in 1983 and was completed in 1990. The seismic-refraction data for the $4,000-\mathrm{km}$, north-south EGT swath from North Cape, Norway, to central Tunisia have been digitized, and analysis and interpretation are progressing. Parts of the results have been published in Tectonophysics. For example, northwest-oriented, thin-skinned tectonic structures in the upper $10 \mathrm{~km}$ of the Variscan crust have been identified from deep seismic reflection in central Europe; the evidence that the $670-\mathrm{km}$ discontinuity is sharp favors its interpretation as a chemical transition between the upper and lower mantle. The EGT offline subproject, Iberian Lithosphere, Heterogeneity and Anisotrophy, cosponsored by CEC, began officially in June 1988. Thirteen broadband seismometers will record data that are to be processed in Madrid, Spain.

As a followup to the EGT project, a network of Earth Science Study Centres was established. The activities of this network concentrate on a series of intensive, residential, 3- to 4-week-long studies that bring younger scientists, research students, and fellows together with more experienced specialists in various disciplines. The aim is to publish the results of the work, as was done after similar study activities in Denmark, Finland, Italy, Switzerland, and Germany.

Networks may be a preparatory phase for more comprehensive activities, as is the one on volcanology. Since 1988, multidisciplinary meetings have been held in Santorin, Greece; Capri, Italy; Punta Delgada, Azores, Portugal; and Lanzarote, Canary Islands, Spain, in order to exchange experiences, share facilities, increase basic knowledge, and model behavior of the active "laboratory" volcanoes, the final goal being to improve the prediction of eruptions. The outcome of this 2-year-long network was a recommendation to the CEC in Brussels to establish a multimillion-dollar project that will increase European involvement in such studies.

New scientific activities of ESF are devoted to strengthening European contributions to several programs. Three activities are being pursued for polar regions under the Global Change Program of the International Council of Scientific Unions (ISCU). The European Polarstern Expedition (EPOS) to Antarctic waters (1986-1991) had aboard in 1988 more than 120 scientists from Western Europe who were studying mainly marine biology but, of course, micropaleontology as well. Europeans are studying Arctic paleoclimates as part of the Polar North Atlantic Margins, Late Cenozoic Evolution, program (PONAM) and the Greenland Icecore Program (GRIP). Additionally,
Europe, under the ESF, began in 1989 its own scientific program on "The European Paleoclimate and Man Since the Last Glaciation."

A very good example of the benefits to be derived by closer European cooperation in the earth sciences was Europe's participation in the Ocean Drilling Program (ODP). In 1986, an ESF consortium of 12 smaller countries became a full member of ODP, thereby joining the classic member countries, the United Kingdom, France, and Germany. As a result of this action, many European earth scientists together with ESF personnel were extremely grateful to ODP for the opportunity to organize and participate in the long-range planning discussions during the second Conference on Scientific Ocean Drilling (COSOD II) that was held in Strasbourg in July 1987.

\section{Looking ahead}

I am very optimistic about "Europe 1992," in spite of the fact that geologists normally add \pm 1 million years to absolute age dates. CEC will spend much more money for scientific projects, institute twinning, and scholarships, for example. ESF plans to participate in organizing postdoctoral exchanges, and in 1990, it established research conferences in Europe similar to the Penrose and Gordon conferences in North America. As a nongovernmental organization, ESF has longtime working relationships with Eastern European academies and currently is pushing an intensification of such activities.

Of course, the efforts to strengthen cooperation and cohesion in European research are not directed toward isolation. To the contrary they are efforts to improve research in the western and eastern parts of the "old house" in order to become a better partner in international research. We have seen, unfortunately, that, confronted with many global problems, neither politics nor economics has produced a consensus, a common language, or a working relationship. Therefore, we as scientists have a special global responsibility because, in the words of the late Andrei Sakharov, the international community of scientists is "the one real worldwide community that exists today." The global problems of today and tomorrow need the attention of this worldwide community that consists both of regional families, such as the European family, the eldest in science, and of special families, such as the International Union of Geological Sciences.

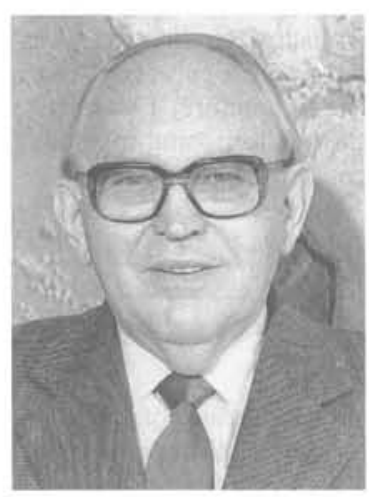

Eugen Seibold, Past President of the IUGS, is a marine geologist well known for his work with the ICSU Scientific Committee on Oceanic Research, Unesco, and a host of other international scientific bodies. While President of the Deutsche Forschungs gemeinschaft, an important research funding agency, Prof. Seibold exerted a major influence on science in Germany. Currently, Prof. Seibold directs the European Science Foundation. 